\title{
KatP, a novel catalase-peroxidase encoded by the large plasmid of enterohaemorrhagic Escherichia coli 0157:H7
}

\author{
Werner Brunder, Herbert Schmidt and Helge Karch
}

Institut für Hygiene und Mikrobiologie der Universităt Wärzburg, Josef-Schneider-Str. 2, 97080 Würzburg, Germany
Author for correspondence: Herbert Schmidt. Tel: +49931201 5160. Fax: +499312013445. e-mail: hschmidt@hygiene.uni-wuerzburg.de catalase-peroxidase, katP

Keywords: enterohaemorrhagic Eschericbia coli O157, plasmid pO157, plasmid-encoded

\section{INTRODUCTION}

Enterohaemorrhagic Escherichia coli (EHEC) O157 is the predominant causative agent of haemorrhagic colitis (HC) and the haemolytic uraemic syndrome (HUS). Foodborne outbreaks and sporadic cases of HC and HUS have been increasing worldwide (Griffin \& Tauxe, 1991; Tarr, 1995; Griffin, 1995). Besides diagnostic and epidemiological approaches, most molecular studies on this pathogen have focused on the function of Shiga-like toxins (O'Brien \& Holmes, 1987; O’Brien et al., 1992; Tesh \& O’Brien, 1991), intimin ${ }_{\mathrm{O} 157}$ (Louie et al., 1993; Yu \&

Abbreviations: EHEC, enterohaemorrhagic Escherichia coli; SLTEC, Shigalike-toxin-producing E. coli; EPEC, enteropathogenic E. coli; EAggEC, enteroaggregative $E$. coli; ETEC, enterotoxigenic $E$. coli; EIEC, enteroinvasive E. coli; HC, haemorrhagic colitis; HUS, haemolytic uraemic syndrome; HP, hydroperoxidase; SLT, Shiga-like toxin.

The EMBL accession number for the sequence reported in this paper is X89017.
Kaper, 1992) and the large plasmid pO157 (Fratamico et al., 1993; Hales et al., 1992; Karch et al., 1987; Toth et al., 1990; Tzipori et al., 1987). While the outer-membrane protein Intimin $_{\mathrm{O157}}$ is involved in the intimate bacterial attachment-effacement of enterocytes in the large intestine (Louie et al., 1993; Griffin, 1995), Shiga-like toxins (SLT) may primarily contribute to the extraintestinal symptoms by receptor-mediated cytotoxic activity to target cells (Tesh \& O'Brien, 1991; Griffin, 1995). Plasmid pO157 is present in almost all clinical EHEC O157 isolates and was first detected in strains causing an outbreak of HC (Wells et al., 1983). Plasmid pO157 has been the subject of several investigations regarding adherence to cultured cells (Dytoc et al., 1993; Karch et al., 1987; Toth et al., 1990), pathogenicity in animal models (Tzipori et al., 1987, 1988; Wadolkowski et al., 1990), and plasmid-encoded functions (Fratamico et al., 1993; Dytoc et al., 1993; Hales et al., 1992). However, the occurrence of this plasmid in clinical isolates could not be linked conclusively to the pathogenic properties of EHEC O157 strains. Recently, we have 
characterized plasmid pO157 of the EHEC O157:H7 strain EDL 933 by restriction mapping and described a pO157-encoded determinant, designated EHEChaemolysin (Schmidt et al., 1995, 1996). EHEChaemolysin is a member of the RTX ( family of pore-forming cytolysins and was recently shown to be cytotoxic for human and bovine cell lines (Bauer \& Welch, 1996).

In the present study, we describe a second pO157-encoded determinant, the EHEC KatP catalase-peroxidase, which is produced in addition to the two chromosomally encoded catalases or hydroperoxidases (HP) of E. coli, HPI and HPII. HPI, which is encoded by the kat $G$ gene, shows bifunctional catalase and peroxidase activity and acts as homotetramer, each subunit of which has a molecular mass of approximately $80 \mathrm{kDa}$ (Triggs-Raine et al., 1988; Triggs-Raine \& Loewen, 1987; Loewen et al., 1985a). E. coli HPI, like other bacterial bifunctional catalase-peroxidases, is a haem-binding enzyme that carries out a variety of functions using hydrogen peroxide as the electron acceptor. In peroxidases, the haem prosthetic group is protoporphyrin IX and the fifth ligand of the haem iron is a histidine. Another histidine residue serves as an acid-base catalyst in the reaction between peroxide and the enzyme. The regions around these two active sites are conserved in a majority of peroxidases (Welinder, 1991).

HPII is encoded by the kat $E$ gene and functions as a catalase only (von Ossowski et al., 1991). Catalases are part of bacterial defence mechanisms against oxidative stress, which involve at least 30 proteins, depending on the stimulus applied (Farr \& Kogoma, 1991). Reactive oxygen molecules, produced as by-products of oxygen metabolism, may damage bacterial cells in many ways (Farr \& Kogoma, 1991). In recent years, superoxide dismutases and catalases expressed by bacterial pathogens have been increasingly thought to protect these pathogens from oxidative damage caused by reactive oxygen molecules produced by phagocytes or other host cells during the infectious process (Welch, 1987; Bortolussi et al., 1987; Beaman \& Beaman, 1984).

\section{METHODS}

Bacterial strains, plasmids and culture conditions. Enterohaemorrhagic E. coli O157:H7 strain EDL 933 was isolated from a patient with $\mathrm{HC}$ and harbours the $93.6 \mathrm{~kb}$ plasmid $\mathrm{PO} 157$ as well as one smaller plasmid of $3.3 \mathrm{~kb}$ (O'Brien et al., 1983; Schmidt et al., 1996). Strain EDL 933-cu was cured of pO157, but not of the smaller plasmid (Tzipori et al., 1987). HPInegative E. coli mutant UM202 (katG17::Tn10) was kindly provided by P. C. Loewen, University of Manitoba, Winnipeg, Manitoba, Canada (Loewen et al., 1985b). E. coli HB101 and $E$. coli DH5a (Gibco BRL) were used as host strains for recombinant plasmids. Diarrhoeagenic $E$. coli isolates used for PCR analysis were from our strain collection. The seven EHEC O157:H7 strains all produced SLT-I, SLT-II, SLT-IIc or combinations of these toxins. The twelve non-O157 Shiga-liketoxin-producing E. coli (SLTEC) belonged to serogroups $\mathrm{O} 26$ (three strains), O111 (three strains), O128 (two strains), O2, $\mathrm{O} 22, \mathrm{O} 52$ and $\mathrm{O} 55$ (one strain each) and also expressed different SLT genotypes. The enteropathogenic E. coli (EPEC) strains were of classical EPEC serogroups O55, O111, O114, O119 and $\mathrm{O} 128$, and were all non-toxigenic. The enteroaggregative $E$. coli (EAggEC) strains all fulfilled the criterion of 'stacked brick'like adherence to HEp-2 cells. The five enterotoxigenic $E$. coli (ETEC) strains expressed heat-stable toxin (ST), heat-labile toxin (LT) or a combination of both toxins. The four enteroinvasive $E$. coli (EIEC) strains were previously identified in our laboratory by the presence of invasion genes located on the large invasion plasmid (data not shown). Plasmids pB26 and $\mathrm{pB} 9$ contain $25.9 \mathrm{~kb}$ and $8.6 \mathrm{~kb}$ Bam HI fragments, respectively, which were derived from pO157 (this study) and cloned in vector pK18 (Pridmore, 1987). Plasmid pUC4K (Pharmacia LKB) was used as donor of the kanamycin-resistance cassette. Cloning of a $9.7 \mathrm{~kb} 5 \mathrm{maI}$ fragment from pO157, which carries the entire EHEC catalase-peroxidase gene in phagemid vector pBluescript IIKS (Stratagene) generated recombinant plasmid pSm10 (this study).

For routine purposes, $E$. coli strains were grown in L-broth $(1 \%$, w/v, tryptone, $0.5 \%$, w/v, yeast extract, $1 \%$, w/v, sodium chloride, $\mathrm{pH} 7 \cdot 5$ ). For preparation of cell extracts, cells were grown in N-broth (nutrient broth), $\mathrm{pH} \mathrm{6.7} \mathrm{(Difco),}$ supplemented with $0.5 \%(\mathrm{w} / \mathrm{v})$ sodium chloride. If necessary, $20 \mu \mathrm{g}$ tetracycline $\mathrm{ml}^{-1}, 100 \mu \mathrm{g}$ ampicillin $\mathrm{ml}^{-1}$ or $50 \mu \mathrm{g}$ kanamycin $\mathrm{ml}^{-1}$ was added to the culture media.

General recombinant DNA methods. Restriction enzymes and T4 DNA ligase were purchased from Gibco BRL, New England Biolabs and Boehringer Mannheim. Plasmid DNA was purified with a Qiagen plasmid Midi kit. For cloning and restriction enzyme analysis, standard procedures were used (Sambrook et al., 1989). Transformation of plasmid DNA was performed according to the method of Hanahan (1983). Purification of DNA fragments from agarose gels was carried out with a Prepa-Gene kit (Bio-Rad). Hybridization experiments were conducted with a digoxigenin labelling and detection kit (Boehringer Mannheim) according to the manufacturers' instructions.

Nucleotide sequencing and sequence analysis. The nucleotide sequence was determined with an automatic sequencer (model 373A; Perkin-Elmer-Applied Biosystems) by Taq cycle sequencing using the Taq DyeDeoxy Terminator Cycle Sequencing kit (Perkin-Elmer-Applied Biosystems) as described previously (Schmidt et al., 1995).

Nucleotide sequence data were obtained by stepwise sequencing. Initially, universal and reverse primers for M13/ pUC18 (Boehringer) were used for sequencing recombinant plasmids $\mathrm{pB} 26$ and $\mathrm{pB} 9$. As new sequence data became available, customized synthetic primers (18- to 22-mers) were utilized (Roth, Karlsruhe, Germany). Both strands of DNA were sequenced completely and each base position was determined on average four times.

Nucleotide sequence analyses and the searches for homologous DNA sequences in the EMBL and GenBank database libraries were performed with the program package HUSAR (Heidelberg Unix Sequence Analysis Resources; German Cancer Research Centre, Heidelberg, Germany), as well as with the DNAsis program (Hitachi Software).

Bacterial cell fractionation. Periplasmic proteins were isolated by the method of Jacobs et al. (1992) with minor modifications. Briefly, bacterial cells were cultured in N-broth at $37^{\circ} \mathrm{C}$ without shaking to an $\mathrm{OD}_{600}$ of $0 \cdot 15-0 \cdot 3$ (approximately $10^{8}$ cells $\mathrm{ml}^{-1}$ ). Cells were harvested by centrifugation $\left(3800 \mathrm{~g}, 15 \mathrm{~min}, 4^{\circ} \mathrm{C}\right.$ ) and resuspended in $30 \mathrm{mM}$ Tris $/ \mathrm{HCl}, \mathrm{pH} 8.0$, containing $27 \%$ $(\mathrm{w} / \mathrm{v})$ sucrose, $0.2 \mathrm{mM}$ EDTA and $1 \%(\mathrm{v} / \mathrm{v}) 2$-phenylethanol (Merck). The suspension was submitted to three cycles of freezing (liquid nitrogen) and thawing $\left(37^{\circ} \mathrm{C}\right.$, water bath) to 
permeabilize the outer membrane of the bacteria. After centrifugation $\left(20000 \mathrm{~g}, 30 \mathrm{~min}, 4^{\circ} \mathrm{C}\right)$, the supernatant was used as periplasmic fraction.

The pellet was resuspended in $20 \mathrm{mM}$ sodium/potassium phosphate buffer, $\mathrm{pH} 7.0$, containing $0.5 \mathrm{mg}$ lysozyme $\mathrm{ml}^{-1}$. After incubation for $10 \mathrm{~min}$ at $30^{\circ} \mathrm{C}$, the cells were lysed by three cycles of freezing (liquid nitrogen) and thawing $\left(37^{\circ} \mathrm{C}\right.$, water bath). DNA was broken down by $50 \mu \mathrm{g} \mathrm{DNaseI} \mathrm{ml}^{-1}$ for $5 \mathrm{~min}$ at $30^{\circ} \mathrm{C}$. Cell debris was removed by centrifugation $\left(20000 \mathrm{~g}, 30 \mathrm{~min}, 4^{\circ} \mathrm{C}\right)$ and the supernatant was used as cytoplasmic fraction. Protein concentrations were estimated by the method of Markwell (1978) with BSA as the standard.

Precipitation of culture supernatants. For precipitation of proteins from culture supernatants, with either ammonium sulfate or trichloroacetic acid (TCA), cells were grown to an $\mathrm{OD}_{600}$ of $0 \cdot 15-0.3$ and centrifuged as described above. For ammonium sulfate precipitation, culture supernatants were filtered through a $0.22 \mu \mathrm{m}$ filter, mixed with ammonium sulfate by slow addition of the same volume of a saturated ammonium sulfate solution and stirred for $1 \mathrm{~h}$ at $4{ }^{\circ} \mathrm{C}$. The precipitate was separated by centrifugation $\left(20000 \mathrm{~g}, 30 \mathrm{~min}, 4^{\circ} \mathrm{C}\right)$, dissolved in $20 \mathrm{mM}$ sodium/potassium phosphate buffer and then used for enzyme assays. For TCA precipitation, TCA was added to a final concentration of $10 \%(w / v)$ to the filtered culture supernatants. After incubation on ice for $1 \mathrm{~h}$ and centrifugation as described above, the TCA precipitate was dissolved in Laemmli sample buffer (Laemmli, 1970) and analysed by SDSPAGE.

Enzyme assay. Peroxidase activity was determined by following the rate of oxidation of the substrate $o$-dianisidine dihydrochloride (Sigma). Measurements were performed in a Hitachi U2000 spectrophotometer at a wavelength of $460 \mathrm{~nm}$ at room temperature. The reaction mixture contained $10 \mathrm{mM}$ sodium/ potassium phosphate buffer, $\mathrm{pH} 7.0,0.3 \mathrm{mg}$ o-dianisidine dihydrochloride $\mathrm{ml}^{-1}, 18 \mathrm{mM} \mathrm{H}_{2} \mathrm{O}_{2}$ and an appropriate amount of protein extract. One enzyme unit is equivalent to an increase in $A_{460}$ of 11.3 units $\mathrm{min}^{-1}$, assuming an absorption coefficient of $11.3 \mathrm{mM}^{-1} \mathrm{~cm}^{-1}$ for 0 -dianisidine (de Mendez et al., 1991). Specific activity was expressed as units per $\mathrm{mg}$ total protein in the assay. Values of enzymic activity were means of triplicate measurements.

Visualization of catalase and peroxidase activities on polyacrylamide gels. Electrophoresis was performed on nondenaturing $8.5 \%(\mathrm{w} / \mathrm{v})$ polyacrylamide gels in a Mini-PROTEAN II Dual Slab Cell (Bio-Rad) at $\mathrm{pH} 8.8$, according to the method of Laemmli (1970). Twenty microgram samples of the protein extracts were adjusted with glycerol and bromophenol blue to final concentrations of $10 \%(\mathrm{v} / \mathrm{v})$ and $0.02 \%(\mathrm{w} / \mathrm{v})$, respectively, and applied to the gel. Electrophoresis was carried out for $5 \mathrm{~h}$ at a constant current of $10 \mathrm{~mA}$. Staining for peroxidase activity was performed as described by Wayne \& Diaz (1986) but instead of diaminobenzidine, 0 -dianisidine $\left(0.3 \mathrm{mg} \mathrm{ml}^{-1}\right)$ was used as electron donor. The activity staining for catalase was carried out as described by Woodbury et al. (1971) with minor modifications: after three washing steps for $15 \mathrm{~min}$ in $\mathrm{H}_{2} \mathrm{O}$, the gels were soaked in $0.03 \% \mathrm{H}_{2} \mathrm{O}_{2}$ for $10 \mathrm{~min}$ and rinsed with $\mathrm{H}_{2} \mathrm{O}$ for $2 \mathrm{~min}$; after this, the gels were incubated in a moist chamber for $15 \mathrm{~min}$ at room temperature to allow consumption of $\mathrm{H}_{2} \mathrm{O}_{2}$ by the catalase bands. The gels were then stained with a freshly prepared solution of $1 \%(\mathrm{w} / \mathrm{v})$ ferric chloride and potassium ferricyanide.

PCR. PCR for detection of EHEC katP sequences was performed with the GeneAmp PCR System 9600 (Perkin-Elmer-Applied Biosystems). Primers wkat-B (5' CTTCCTGTTCTGA TTCT'TCTGG $3^{\prime}$ ) and wkat-F (5' AACT'TATT'TC'TCGCATCATCC $3^{\prime}$ ) were designed to amplify a $2125 \mathrm{bp}$ fragment of the
EHEC katP gene. Briefly, $10^{4}$ bacterial cells derived from a single colony were suspended in $40 \mu \mathrm{l}$ saline $(0.85 \%$ sodium chloride). PCR was performed in a total volume of $50 \mu \mathrm{l}$ containing $5 \mu \mathrm{l}$ of the bacterial cell suspension, $30 \mathrm{pmol}$ of each primer, $200 \mu \mathrm{M}$ of each deoxyribonucleoside triphosphate, $5 \mu \mathrm{l}$ GeneAmp 10-fold concentrated PCR buffer II, $3 \mu \mathrm{l} 25 \mathrm{mM}$ $\mathrm{MgCl}_{2}$ and 2 units of AmpliTaq DNA polymerase (PerkinElmer-Applied Biosystems). After an initial denaturation of $5 \mathrm{~min}$ at $94^{\circ} \mathrm{C}$, the samples were subjected to 30 cycles of amplification, each of which consisted of $30 \mathrm{~s}$ at $94^{\circ} \mathrm{C}, 60 \mathrm{~s}$ at $56^{\circ} \mathrm{C}$ and $150 \mathrm{~s}$ at $72^{\circ} \mathrm{C}$. The reaction was completed with a final extension step of $5 \mathrm{~min}$ at $72^{\circ} \mathrm{C}$. Ten microlitres of the PCR products was mixed with gel-loading buffer and electrophoresed on $0.6 \%(\mathrm{w} / \mathrm{v})$ agarose gels.

\section{RESULTS}

\section{Cloning and sequence analyses of the EHEC katP gene}

In order to characterize the large plasmid of $E$. coli O157:H7 strain EDL 933 at a molecular level, we constructed several subclones in vector $\mathrm{pK} 18$ and performed partial sequence analysis of these clones with universal and reverse sequencing primers. By using subclones pB26 and pB9, which harbour pO157-derived $25.9 \mathrm{~kb}$ and $8.6 \mathrm{~kb}$ Bam HI restriction fragments, we found nucleotide sequence similarities $(>50 \%)$ to the catalaseperoxidase genes of E. coli, Salmonella typhimurium, Mycobacterium spp., Bacillus stearothermopbilus and Rbodobacter capsulatus. This prompted us to investigate these putative catalase sequences more systematically, since no plasmidborne catalase of an obligate bacterial pathogen has been described to date.

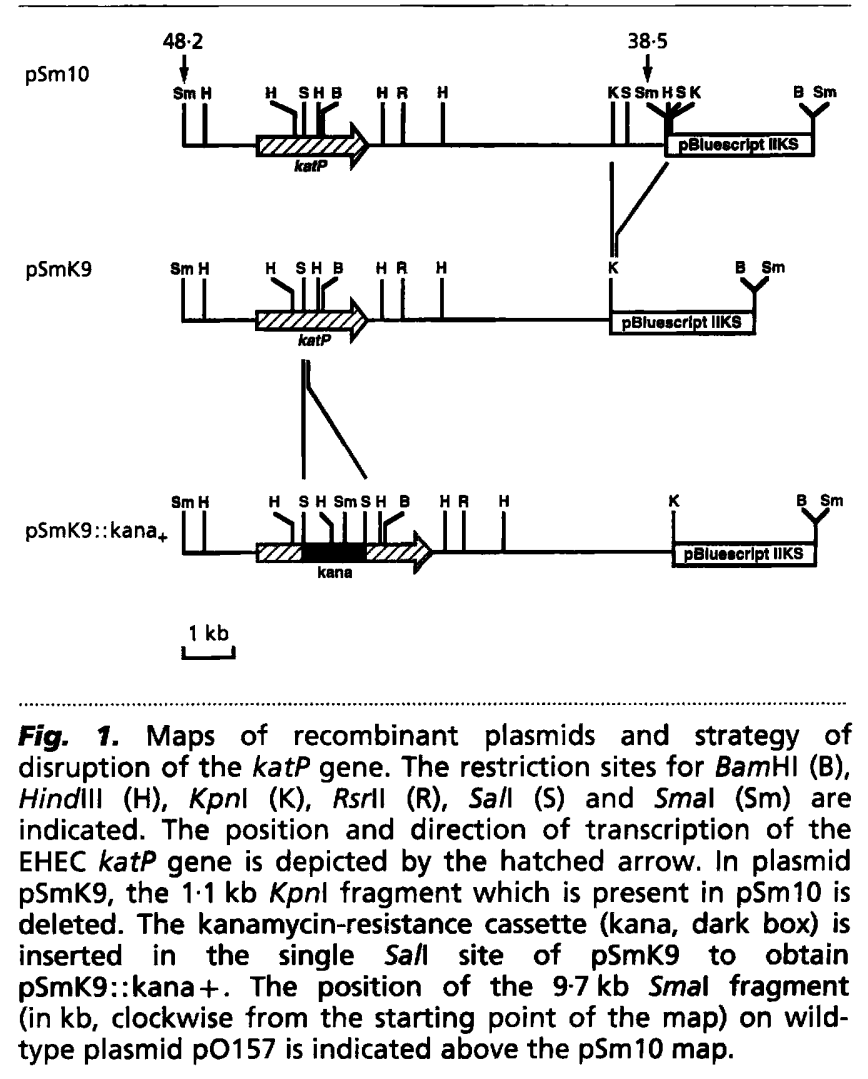


1 GTTGCGGCTIGGAACCCTIAGTATTTTTTGTCTGTAGTATCTATCCCAGCAATAGgTATATCCTGTTGCATCAATAAAGTTGACTTTTGTATACAACAT

101 GCGAATITCCCTTAATCCGGAGCTATTCGTATGATAAAAAAAACTCTTCCTGTTCTGATTCTTCTGGCGCTATCGGGAGCTTTTCTACCGCTGTAGCCG 1 SD $M$ I $K$ K 201 CTGATAAAAAAGAGACTCAAAATTTCTACTATCCAGAAACACTGGATTTAACTCCTCTGAGATTACACAGCCCTGAATCAAATCCCTGGGGGGCTGATTT $\begin{array}{llllllllllllllllllllllllllllllllll}25 & \text { D } & \text { K } & \text { K } & \text { E } & \text { T } & \text { Q } & \text { N } & \text { F } & \text { Y } & \text { Y } & \text { P } & \text { E } & \text { T } & \text { L } & \text { D } & \text { L } & \text { T } & \text { P } & \text { L } & R & \text { L } & \text { H } & \text { S } & \text { P } & \text { E } & \text { S } & \text { N } & \text { P } & \text { W } & G & \text { A } & \text { D } & F\end{array}$ 301 TGATTATGCCACCAGATTTCAACAGCTGGATATGGAGGCTCTGAAAAAGATATCAAAGATTTGCTGACAACTTCCCAGGATTGGTGGCCTGCGGATTAT

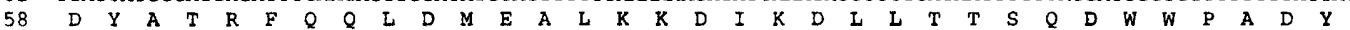

401 GGTCATTATGGTCCTTTCTTTATTCGTATGGCTTGGCACGGTGCCGGAACATACAGGACATATGATGGCCGGGGAGGCGCCAGTGGTGGTCAGCAACGTT

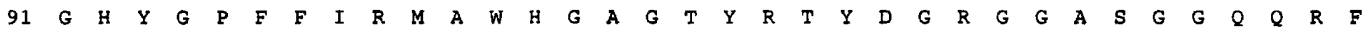
501 TTGAACCGCTGAACAGCTGGCCGGATAACGTTAATCTGGATAAAGCCCGTCGATTGCTGTGGCCAGTCAAGAAAAAATACGGCTCCAGTATTTCCTGGGG $\begin{array}{lllllllllllllllllllllllllllllllll}\mathbf{E} & \mathbf{P} & \mathbf{L} & \mathbf{N} & \mathbf{S} & \mathbf{W} & \mathbf{P} & \mathbf{D} & \mathbf{N} & \mathbf{V} & \mathbf{N} & \text { L } & \mathbf{D} & \mathbf{K} & \mathbf{A} & \mathbf{R} & \mathbf{R} & \text { L } & \text { L } & \text { W } & \mathbf{P} & \mathbf{V} & \mathbf{K} & \mathbf{K} & \mathbf{K} & \mathbf{Y} & \mathbf{G} & \mathbf{S} & \mathbf{S} & \text { I } & \mathbf{S} & \mathbf{W} & G\end{array}$ CAATCCTGAAGGCCCCGGTGGAAAACAGATCCTCTGGCTTCCGCGAAAGATATCAGGGAAGCTTTTTCACGTATGGCCATGGATGATGAGGAGACTGT

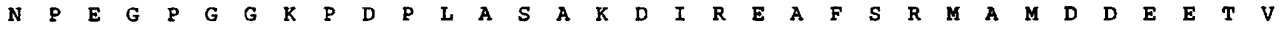
901 GGCCCTGATCGCGGGAGGGCATACATTTGGTAAAGCACATGGTGCAGCGTCTCCTGAAAAATGTATTGGCGCAGGGCCTGATGGTGCACCTGTGGAGGAG

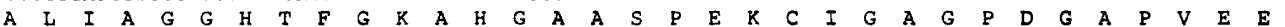
CAGGGACTGGGATGGAAAAATAAATGTGGTACAGGAAACGGCAAATATACCATCACCAGTGGCCTGGAAGGAGCCTGGTCGACATCGCCAACCCAGTTCA

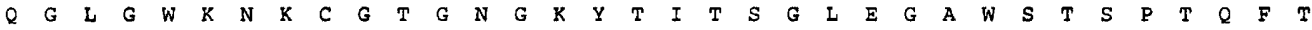
CAATGCAGTATCTGAAGAATTTATATAAATATGAATGGGAGCTGCACAAGAGTCCTGCCGGTGCTTATCAGTGGAAGCCTAAAAAAGCGGCAAATATAGT $\begin{array}{lllllllllllllllllllllllllllllllll}\mathbf{M} & \mathbf{Q} & \mathbf{Y} & \mathbf{L} & \mathbf{K} & \mathbf{N} & \mathbf{L} & \mathbf{Y} & \mathbf{K} & \mathbf{Y} & \mathbf{E} & \mathbf{W} & \mathbf{E} & \mathbf{L} & \mathbf{H} & \mathbf{K} & \mathbf{S} & \mathbf{P} & \mathbf{A} & \mathbf{G} & \mathbf{A} & \mathbf{Y} & \mathbf{Q} & \mathbf{W} & \mathbf{K} & \mathbf{P} & \mathbf{K} & \mathbf{K} & \mathbf{A} & \mathbf{A} & \mathbf{N} & \mathbf{I} & \mathbf{V}\end{array}$ TCAGGACGCGCATGATCCGTCTGTCCTGCATCCGTTGATGATGTTTACGACGGATATTGCTCTTAAAGTTGATCCTGAATATAAGAAAATAACCACCCGT

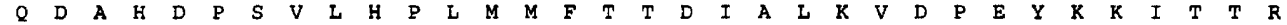

1301 TTCCTGAATGATCCAAAAGCTTTTGAGCAGGCATTCGCAAGAGCATGGTTTAAACTGACCCACCGGGATATGGGACCGGCAGCCCGATATCTTGGTAATG $\begin{array}{lllllllllllllllllllllllllllllllllll}391 & F & L & N & D & P & K & A & F & E & Q & A & F & A & R & A & W & F & K & L & T & H & R & D & M & G & P & A & A & R & Y & L & G & N & E\end{array}$ 1401 AAGTTCCTGCAGAATCATTTATCTGGCAGGATCCTCTTCCTGCGGCGGATTATACAATGATTGATGGTAAAGACATTAAGTCGCTGAAAGAGCAGGTTAT $\begin{array}{llllllllllllllllllllllllllllllllll}425 & V & P & A & E & S & F & I & W & Q & D & P & \text { L } & \text { P } & \text { A } & \text { A } & \text { D } & \text { Y } & \text { T } & \text { M } & \text { I } & \text { D } & G & K & D & I & K & S & \text { L } & K & E & Q & V & M\end{array}$ 1501 GGATTTGGGATCCCTGCATCTGAGCTGATAAAGACAGCCTGGGCTTCAGCTTCCACATTTCGTGTGACTGATTATCGTGGGGGAATAATGGTGCCCGC

Fig. 2. Nucleotide sequence of the EHEC katP gene. The DNA translation is shown in the one-letter code below the nucleotide sequence, at the first nucleotide of every codon. The putative Shine-Dalgarno (SD) and terminator sequences are indicated. The locations of the PCR-primer-binding sites are depicted by arrows above the nucleotide sequence.

Nucleotide sequencing of the two aforementioned DNA fragments with customized primers revealed further catalase-peroxidase-specific nucleotide sequences. Therefore, it was concluded that the putative catalase gene overlapped both the $25.9 \mathrm{~kb}$ and $8.6 \mathrm{~kb} \mathrm{BamHI}$ restriction fragments which are located consecutively on pO157
(Schmidt et al., 1996). To clone the entire gene on a single fragment, we ligated a $9.7 \mathrm{~kb} S m a \mathrm{I}$ fragment, which included the respective Bam HI site, into the vector pBluescript IIKS. The resulting plasmid was designated pSm10 (Fig. 1). The SmaI fragment covered the region from 38.5 to $48.2 \mathrm{~kb}$ in the pO157 map (Schmidt et al., 
Table 1. Amino acid sequence identities and weighted similarities of the EHEC 0157:H7 plasmid-encoded catalase-peroxidase KatP to other bacterial bifunctional catalase-peroxidases

Values of percentage identity, percentage similarity and residues aligned were calculated with the program GAP from the HUSAR software package.

\begin{tabular}{|lccccl|}
\hline Organism & Enzyme & $\begin{array}{c}\text { Identity } \\
\mathbf{( \% )}\end{array}$ & $\begin{array}{c}\text { Similarity } \\
\mathbf{( \% )}\end{array}$ & $\begin{array}{c}\text { Residues } \\
\text { aligned }\end{array}$ & Reference \\
\hline Bacillus stearothermophilus & PerA & 59 & 69 & 708 & Loprasert et al. $(1989)$ \\
Mycobacterium intracellulare & MI85 & 56 & 67 & 713 & Morris et al. (1992) \\
Eschericbia coli & KatG (HPI) & 55 & 67 & 689 & Triggs-Raine et al. (1988) \\
Mycobacterium tuberculosis & KatG & 55 & 66 & 715 & Heym et al. (1993) \\
Salmonella typbimurium & KatG (HPI) & 54 & 66 & 689 & Loewen \& Stauffer (1990) \\
Rhodobacter capsulatus & CpeA & 43 & 47 & 562 & Forkl et al. (1993) \\
\hline
\end{tabular}

1996). By further use of customized oligonucleotides, we sequenced $2407 \mathrm{bp}$ from both strands of this fragment (Fig. 2). This sequence was analysed for ORFs with the DNAsis software package. A single ORF of 2208 bp was found beginning with ATG at position 131 and ending with TGA; the last nucleotide (A) is found at position 2341. This ORF is preceded by a potential ribosomebinding site with the sequence GGAG spanning position 119-122, 8 bp upstream from the ATG start codon. A potential rho-independent terminator sequence (Rosenberg \& Court, 1979) containing a 10 bp hyphenated dyad with a calculated $\Delta G^{0 \prime}$ of $-76.6 \mathrm{~kJ} \mathrm{~mol}^{-1}$ was found $8 \mathrm{bp}$ downstream from the translational stop codon (Fig. 2).

Restriction analysis of the $9.7 \mathrm{~kb} S m a \mathrm{I}$ fragment with the enzymes BamHI, HindIII, KpnI, RsrII and SalI, and comparison of the fragment patterns obtained with the restriction sites deduced from the nucleotide sequence, as well as hybridization with specific probes, allowed us to determine the position of the ORF within the fragment. All of the restriction enzyme sites expected from the nucleotide sequence were found (Fig. 1).

The nucleotide sequence of the ORF predicted a putative protein of 736 amino acids with a molecular mass of $81.8 \mathrm{kDa}$ and a calculated isoelectric point of 5.97 . By comparing this amino acid sequence with sequences of the SwissProt database library, significant identities and similarities were found with several bacterial bifunctional catalase-peroxidases (Table 1). The newly discovered EHEC catalase was termed KatP because of its genetic determination on plasmid pO157 (katP) as well as to distinguish it from the E. coli chromosomal HPI (KatG) and HPII (KatE) catalases.

We investigated the KatP amino acid sequence for the presence of catalase-peroxidase-specific signatures and found that the peroxidase 2 motif covered positions 94-105, and the peroxidase 1 motif positions 256-266 (Welinder, 1991).

By comparing the amino acid sequences of different bacterial catalase-peroxidases with that of the putative
EHEC KatP protein, we found the $\mathrm{N}$ termini of all investigated proteins to be highly variable. Analysis of the first 20-30 amino acids with the method developed by von Heijne (1986) revealed a typical signal peptide for EHEC KatP with the sequence MIKKTLPVLILLALSGSFSTAVA. The signal sequence includes two positively charged lysine residues close to the amino terminus (residues 3 and 4) and a non-polar core region spanning residues $6-14$. The putative cleavage site is located between position 23 and 24 of the amino acid sequence.

\section{Quantitative determination of the peroxidase activity of wild-type and cloned KatP}

Since KatP possesses an amino-terminal signal peptide, it was likely to be transported through the cytoplasmic membrane. Therefore, periplasmic and cytoplasmic fractions, as well as culture supernatants, were investigated separately. First, the expression of EHEC katP was investigated by determining the specific periplasmic and cytoplasmic peroxidase activity of $E$. coli $\mathrm{DH} 5 \alpha / \mathrm{pSm} 10$ $\left(\mathrm{Kat}^{+}\right)$using $o$-dianisidine as the substrate. The cytoplasmic peroxidase activity of this strain was twofold higher, whereas its periplasmic peroxidase activity was $20-30$-fold higher when compared with vector control $E$. coli $\mathrm{DH} 5 \alpha / \mathrm{pB}$ luescript IIKS. This increased peroxidase activity could be caused by (i) the enzymic activity of $\mathrm{KatP}$, or (ii) a regulatory effect of the pSm10 DNA on the expression of the chromosomal kat $G$ gene.

In order to prove that the increased peroxidase activity of $\mathrm{DH} 5 \alpha / \mathrm{pSm} 10$ is determined by the katP gene and not by other putative genes that may be located on the $9.7 \mathrm{~kb}$ $S m a I$ fragment of $\mathrm{pSm} 10$, we inactivated kat $P$ by insertion of a kanamycin-resistance cassette derived from pUC4K in the single Sall site of the gene. Moreover, to exclude possible polar effects of the kanamycin-resistance cassette on DNA located downstream of katP, it was inserted in both orientations. Since plasmid pSm10 contains two further Sall sites (Fig. 1), these had to be removed prior to insertion of the kanamycin-resistance cassette in the katP gene. To do this, we restricted pSm10 with KpnI, removed the $1.1 \mathrm{~kb} K p n \mathrm{I}$ fragment by agarose gel electrophoresis, 


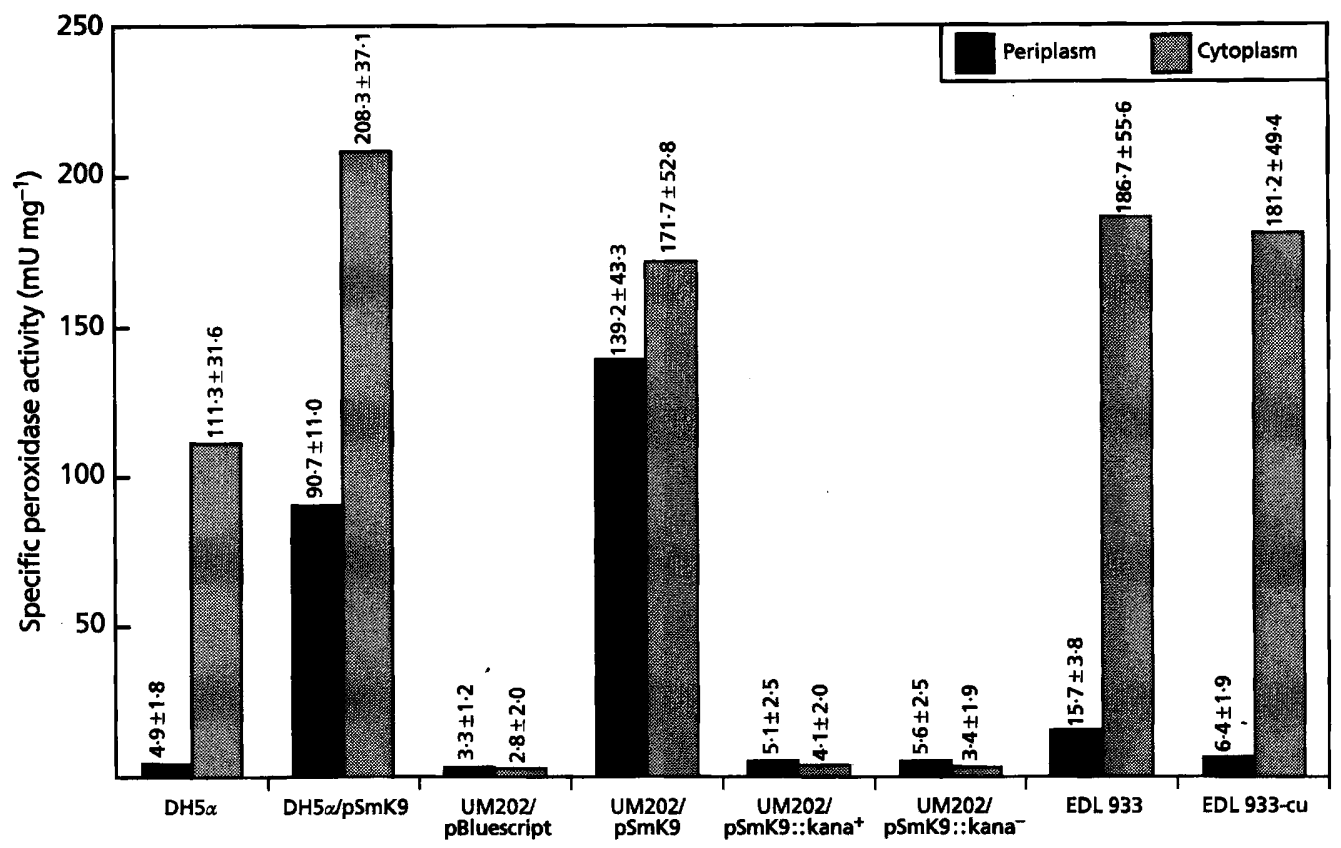

Fig. 3. Specific peroxidase activities of test strains. Values of specific peroxidase activity [mU (mg total protein) ${ }^{-1}$ ] are depicted above the respective columns together with standard deviations. Values are means of triplicate measurements.

and religated the remaining plasmid to obtain $\mathrm{pSmK} 9$ (Fig. 1). After excision of the kanamycin-resistance cassette from pUC4K with Sall, it was inserted in the single Sall site of $\mathrm{pSmK} 9$. The resulting clone was designated pSmK9::kana + (Fig. 1). The correct insertion of the kanamycin-resistance cassette was verified by kat $P$-specific PCR, restriction endonuclease digestion and DNA sequencing.

To overcome the effects of chromosomal peroxidase HPI of host strain DH5 $\alpha$ and to exclude regulatory effects of pSmK9 on the chromosomal kat $G$ gene, HPI-negative $E$. coli mutant UM202 was used for additional experiments. Fig. 3 shows the results obtained when specific peroxidase activity was determined in periplasmic and cytoplasmic crude extracts of cloned kat $P$ in several $E$. coli hosts and controls. In the control strain DH5 $\alpha$, peroxidase activity was primarily found in the cytoplasmic fraction (Fig. 3). Following transformation with pSmK9 $\left(k a t P^{+}\right)$, cytoplasmic activity increased twofold. In contrast to DH $5 \alpha$, high periplasmic peroxidase activity could be observed (Fig. 3), which is in the same range as for pSm10. The specific peroxidase activity of vector control $E$. coli UM202/pBluescript IIKS was very weak, as expected from the mutation in the katG gene (Fig. 3). In UM202/pSmK9 $\left(k a t P^{+}\right)$, cytoplasmic peroxidase activity increased 60 -fold, whereas the periplasmic activity increased 40-fold (Fig. 3). Disruption of the katP gene in UM202/pSmK9:: kana + resulted in low cytoplasmic and periplasmic peroxidase levels, which were similar to those of the vector control strain UM202/pBluescript IIKS. Furthermore, measurements of peroxidase activities of strain UM202/pSmK9:: kana - carrying the kanamycin- resistance cassette inserted in the opposite orientation, were in the same range as in UM202/pSmK9::kana + (Fig. 3). When the peroxidase activity of wild-type strain EDL 933 and EDL 933-cu was determined, the same high levels of cytoplasmic activity were found in both strains. However, there were differences in the periplasmic fraction. Periplasmic peroxidase activity in EDL 933 was clearly higher than in strain EDL 933-cu. These experiments indicated that the enhanced peroxidase levels observed in strains DH5 $\alpha / \mathrm{pSmK} 9, \mathrm{UM} 202 / \mathrm{pSmK} 9$ and wild-type EDL 933 are the result of the enzymic activity of KatP.

Peroxidase activity was also determined in culture supernatants of the test strains. The tests were performed with native culture supernatants and with concentrated culture supernatants prepared by ammonium sulfate precipitation. Furthermore, these fractions (and in addition TCA-precipitated supernatants) were investigated for the KatP protein by SDS-PAGE. None of the supernatants and precipitates showed either peroxidase activity or the $80 \mathrm{kDa}$ band (as expected in the presence of the KatP protein). No activity was detected by peroxidase and catalase stainings of culture supernatants and precipitates in non-denaturing gels (data not shown).

\section{Visualization of catalase and peroxidase activities of recombinant strains on non-denaturing gels}

Cytoplasmic and periplasmic crude extracts from the strains described above were separated on polyacrylamide gels under non-denaturing conditions. The gels were stained with either $o$-dianisidine (for peroxidase activity) 
(a)

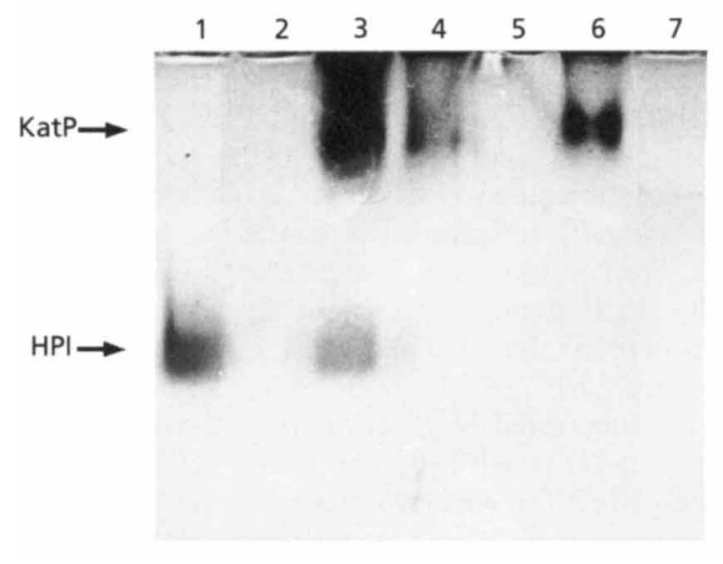

(b)

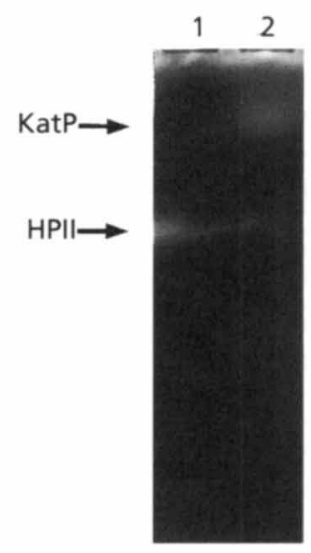

(c)

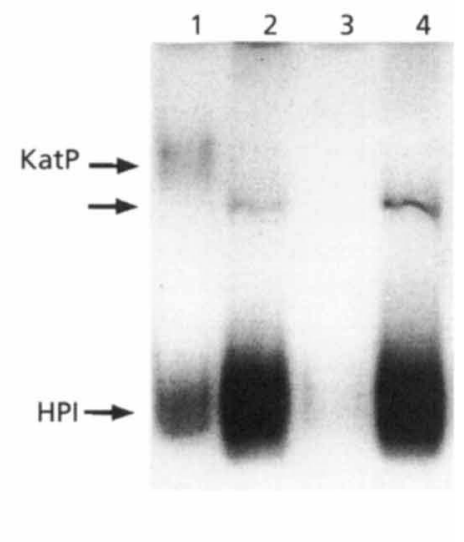

Fig. 4. (a) Peroxidase activity stain after non-denaturing gel electrophoresis of periplasmic (pp) and cytoplasmic (cp) fractions from test strains. Lane 1, E. coli DH5 $\alpha$ (cp), lane 2 (pp); lane 3, DH5 $\alpha / p S m K 9$ (cp), lane 4 (pp); lane 5, UM202/pBluescript IIKS, (pp); lane 6, UM202/pSmK9 (pp); lane 7, UM202/pSmK9::kana + (pp). (b) Catalase activity stain after non-denaturing electrophoresis of periplasmic fractions from strains UM202/pBluescript IIKS (lane 1) and UM202/pSmK9 (lane 2). The gels shown in (a) and (b) were run together and stained separately for enzymic activity. (c) Peroxidase activity stain after non-denaturing gel electrophoresis of periplasmic (pp) and cytoplasmic (cp) fractions from E. coli 0157:H7 strain EDL 933, lane 1 (pp), lane 2 (cp) and EDL 933-cu, lane 3 (pp), lane 4 (cp). HPI, HPII, KatP and the additional peroxidase band are indicated by arrows.

or ferricyanide (for catalase activity). Fig. 4(a) shows peroxidase-activity-stained gels with cytoplasmic and periplasmic crude extracts from our test strains.

Crude extracts from strains harbouring pSmK9 demonstrated an additional slow-migrating band (Fig. 4a, lanes 3 , 4 and 6), which was not present in control strains without pSmK9 (Fig. 4a, lanes 1, 2 and 5). This band was detectable in both cytoplasmic and periplasmic fractions. The occurrence of this band seemed not to be influenced by simultaneously expressed katG (HPI).

Disruption of the katP gene in strain UM202/ pSmK9:: kana + resulted in a lack of the additional band which was observed in $\mathrm{KatP}^{+}$strains (Fig. 4a, lane 7). Therefore, this additional band with peroxidase activity was concluded to be the KatP protein. Interestingly, chromosomal HPI peroxidase activity of E. coli DH $5 \alpha$ was detected only in the cytoplasmic fraction (Fig. 4a, lanes 1 and 3).

Fig. 4(b) shows catalase activity staining of periplasmic crude extracts of UM202/pBluescript IIKS (lane 1) and UM202/pSmk9 (lane 2). Aside from the weak catalase activity of $E$. coli HPII, strain UM202/pSmK9 also expresses a second catalase activity with the same migration rate as the additional band occurring in the aforementioned peroxidase-staining experiments. Together with the sequence analyses, these experiments indicate that the EHEC KatP protein acts as a bifunctional catalase-peroxidase.

\section{Visualization of KatP expressed by wild-type strain EDL 933}

When peroxidase activity stainings were performed with crude extracts of wild-type EHEC O157:H7 strain EDL 933 and its cured derivative EDL 933-cu, the KatP band was detected exclusively in the periplasmic fraction of EDL 933 (Fig. 4c, lane 1). This band was lacking in both fractions of EDL 933-cu (Fig. 4c, lanes 3 and 4). Unexpectedly, both strains showed a further band with a migration rate different from that of HPI or KatP (Fig. 4c, lanes 2 and 4). This band occurred strictly in the cytoplasmic fraction and was not detected in any of the other strains tested. Therefore, this indicates a third protein with peroxidase activity, which presumably is encoded by the chromosome or the $3.3 \mathrm{~kb}$ plasmid of EDL 933. To get more information about the origin of this additional band, we tested $E$. coli O157:H7 strain A $8993 / \mathrm{CS} 2$, which lacks the $3.3 \mathrm{~kb}$ plasmid, by peroxidase activity staining. The same band with different migration rates from HPI and KatP as in EDL 933 was found in this strain.

\section{Survival experiments}

To assess the biological function of the KatP enzyme, $\mathrm{H}_{2} \mathrm{O}_{2}$-challenge experiments were performed with EDL 933 and its cured derivative EDL933-cu using three different methods. (i) Viable cell counts were determined after treatment of mid-exponential-phase cultures with different concentrations of $\mathrm{H}_{2} \mathrm{O}_{2}$ (Storz \& Toledano, 1994). (ii) Overnight cultures of the test strains were 
Table 2. Detection of the katP catalase-peroxidase gene in diarrhoeagenic $E$. coli by PCR with primers wkat-B and wkat-F

Strains were defined as being positive when the expected $2125 \mathrm{bp}$ PCR product was detected and could be restricted with Bam HI into a $1.3 \mathrm{~kb}$ and a $0.85 \mathrm{~kb}$ fragment. Haemolytic activity was screened on blood-agar plates as described by Schmidt $e t$ al. (1994a). Detection of Shiga-like toxin genes was performed as described previously (Schmidt et al., 1994b).

\begin{tabular}{|lcccr|}
\hline Pathogroup & $\begin{array}{c}\text { No. of } \\
\text { strains }\end{array}$ & $\begin{array}{c}\text { katP } \\
\text { PCR* }\end{array}$ & Haemolysis & slt \\
\hline EHEC (O157) & 7 & 7 & $7(7) \dagger$ & 7 \\
SLTEC (non-O157) & 12 & 2 & $10(8) \dagger$ & 12 \\
EPEC & 15 & 0 & 0 & 0 \\
ETEC & 5 & 0 & 0 & 0 \\
EIEC & 4 & 0 & 0 & 0 \\
EAggEC & 20 & 0 & $2(0) \dagger$ & 0 \\
\hline
\end{tabular}

* All katP-positive strains show also the enterohaemolytic phenotype.

†The numbers of enterohaemolytic strains are given in brackets, the haemolytic phenotype of the other strains resembles alphahaemolysin.

plated on an agar plate in $3 \mathrm{ml}$ soft agar and a disc impregnated with $5 \mu \mathrm{l}$ of different $\mathrm{H}_{2} \mathrm{O}_{2}$ solutions (up to a concentration of $30 \% \mathrm{v} / \mathrm{v}$ ) was placed in the centre of the agar plate. After overnight incubation at $37^{\circ} \mathrm{C}$, the zones of inhibition were determined (zone of inhibition assay) (Storz \& Toledano, 1994). (iii) The bacteria were spread across a $\mathrm{H}_{2} \mathrm{O}_{2}$-gradient agar plate using sterile cotton swabs. Resistance was scored as the length of growth into the gradient (Brown et al., 1995). No significant differences in $\mathrm{H}_{2} \mathrm{O}_{2}$ resistance were observed between EDL 933 and EDL 933-cu by any of the methods used. However, both strains were more $\mathrm{H}_{2} \mathrm{O}_{2}$ resistant than the laboratory strain $\mathrm{DH} 5 \alpha$.

\section{Screening of diarrhoeagenic $E$. coli for the presence of the katP gene by PCR}

To investigate the distribution of the katP gene in diarrhoeagenic $E$. coli, a PCR assay was developed. Primers wkat-B (nt 145-167, sense strand) and wkat-F (nt 2251-2271, antisense strand) were designed to amplify a 2125 bp fragment of the EHEC-katP gene (see Fig. 2). The primer-binding sites were selected from regions of low similarity after comparison of the kat $P$ sequence with catalase-peroxidase sequences available from the EMBL/ GenBank database libraries. The specificity of the PCR assay was tested with kat $G$-positive $E$. coli strains HB101, DH5 $\alpha$ and EDL 933-cu, these strains being negative by PCR. Therefore, none of the chromosomal catalase genes $k a t G$ and kat $E$ were amplified by the PCR assay used here. Strains DH5 $\alpha / \mathrm{pSmK} 9$ and EDL 933 were positive by PCR. All PCR products were verified by restriction enzyme digestion with $B a m \mathrm{HI}$, creating $1.3 \mathrm{~kb}$ and $0.85 \mathrm{~kb}$ restriction fragments, in accordance with the nucleotide sequence of katP.

Following this, representative strains of the major groups of diarrhoeagenic E. coli, including EPEC, EIEC, ETEC, EAggEC, EHEC and SLTEC of other serogroups than O157 were subjected to PCR analysis using primers wkat$B$ and wkat-F, followed by restriction analysis with BamHI. The results of these experiments (Table 2) indicate that the katP gene is prevalent in EHEC strains of serogroup O157 that also harbour the EHEC-haemolysin operon. All kat $P^{+} \mathrm{O} 157$ strains have also been shown to express a functional KatP protein by activity tests. By testing non-O157 SLTEC we found $1 / 3 E$. coli O26 strains and $1 / 3 E$. coli $\mathrm{O} 111$ strains to be kat $P$-positive. These strains were also enterohaemolytic. The EPEC, ETEC, EIEC and EAggEC strains tested here were all negative by the katP-specific PCR assay.

\section{DISCUSSION}

We have detected and characterized a new catalaseperoxidase (KatP) of enterohaemorrhagic E. coli O157, which is produced in addition to the known E. coli catalases HPI and HPII. The results of sequence analyses and activity tests categorize KatP, like E. coli HPI, as a member of the bacterial bifunctional catalase-peroxidase family. Although KatP and HPI share high sequence similarity and a similar molecular mass, their electrophoretic mobilities on non-denaturing gels differ markedly. One explanation for this phenomenon could be that the active forms of HPI and KatP consist of different subunit numbers.

Amino acid analyses of the $\mathrm{N}$ termini of KatP and other members of the bifunctional catalase-peroxidase family revealed a typical signal sequence only for KatP. However, this was not demonstrated for the other members. Such signal sequences are required for Sec-dependent transport of bacterial proteins through the cytoplasmic membrane. In Gram-negative bacteria, those proteins may then be located in the periplasm or be translocated through the outer membrane by the action of additional transport systems (Salmond \& Reeves, 1993). Therefore, catalase and peroxidase activities of KatP were investigated in cytoplasmic and periplasmic crude extracts as well as in culture supernatants. Culture supernatants of test strains did not reveal any catalase or peroxidase activity. Furthermore, supernatants, which were precipitated with TCA and separated on denaturing polyacrylamide gels, did not reveal the expected $80 \mathrm{kDa}$ band of KatP. However, we found good evidence that KatP is located primarily in the periplasm in wild-type $E$. coli EDL 933. Comparison of this strain with its plasmidcured derivative, EDL 933-cu, showed that crude extracts of EDL 933 had higher periplasmic peroxidase activity, whereas both strains shared similar cytoplasmic peroxidase activity levels. In addition, non-denaturing gel electrophoresis of crude extracts of EDL 933 revealed the presence of the KatP band in the periplasmic fraction but not in the cytoplasmic fraction. 
The HPI catalase-peroxidase, reportedly a periplasmic enzyme (Heimberger \& Eisenstark, 1988) was primarily found in the cytoplasmic fraction with the preparation method used here. Only trace amounts of HPI were detected in the periplasmic fractions of EDL 933 and DH5 $\alpha$. These findings are in contrast to that of Heimberger \& Eisenstark (1988), who found HPI in periplasmic and membrane fractions. This may be the result of different preparation methods.

Periplasmic and cytoplasmic peroxidase activities were very high in strains DH5 $\alpha$ and UM202, which harbour plasmid pSmK9. High levels of enzymic activity in these strains may be due to a gene-dose effect caused by the high copy number of vector pBluescript IIKS.

Since UM202 is HPI negative, peroxidase activity of UM202/pSmK 9 must be caused by KatP alone. The high cytoplasmic peroxidase activity of UM202/pSmK9 was unexpected, since KatP was thought to function primarily in the periplasm in wild-type EDL 933. A possible explanation for this phenomenon may be that the export rate could not keep up with the high cytoplasmic expression of the KatP protein. As a result, there would be an accumulation of KatP in the cytoplasm.

Members of the bifunctional catalase-peroxidase family have been described in E. coli (Triggs-Raine et al., 1988), Mycobacterium spp. (Morris et al., 1992; Heym et al., 1993), Salmonella typhimurium (Loewen \& Stauffer, 1990), Bacillus stearothermophilus (Loprasert et al., 1989), and Rbodobacter capsulatus (Forkl et al., 1993). In all the aforementioned examples, the catalase-peroxidases are encoded on the chromosome. This is the first description of a periplasmic catalase-peroxidase encoded by a plasmid of an obligate bacterial pathogen. Periplasmic catalases have been described in phytopathogenic strains of Pseudomonas syringae. These bacteria contain multiple catalases, which are found in the cytoplasm, periplasm and the membrane fraction. The production of multiple catalases is highly correlated with the ability of $P$. syringae to colonize plant tissues (Klotz \& Hutcheson, 1992).

Upon physical contact with bacteria or bacterial structures, macrophages and neutrophils produce cytotoxic oxidants during the so-called oxidative burst. It has been suggested that bacterial catalases and superoxide dismutases detoxify these agents, therefore preventing the infecting bacteria from being damaged. Catalase-mediated defence against reactive oxygen molecules represents a possible virulence factor for pathogens that have the ability to invade host cells, i.e. macrophages. This has been investigated in Listeria monocytogenes (Goebel et al., 1993; Myers et al., 1993), Salmonella typhimurium (Kagaya et al., 1992), Shigella flexneri (Franzon et al., 1990) and Mycobacterium tuberculosis (Beaman \& Beaman, 1984).

To assess a function of the KatP enzyme for EHEC O157: $\mathrm{H} 7$ strains, $\mathrm{H}_{2} \mathrm{O}_{2}$-challenge experiments were performed. No significant differences in $\mathrm{H}_{2} \mathrm{O}_{2}$ resistance were observed between EDL 933 and EDL 933-cu. However, both strains were more $\mathrm{H}_{2} \mathrm{O}_{2}$ resistant than the laboratory strain DH5 $\alpha$. Therefore, only minor effects of the KatP enzyme on EDL 933 could be observed in vitro.
At present, two determinants of the large plasmid pO157 have been molecularly characterized, the EHEChaemolysin and the EHEC KatP catalase-peroxidase. The occurrence of both determinants seems to be restricted to Shiga-like-toxin-producing E. coli, as shown in this and in previous studies. Both proteins may have the potential to enhance the virulence of EHEC O157 strains. However, in vitro and, in particular, in vivo tests need to be conducted to address the functions of EHEC-haemolysin and KatP catalase-peroxidase to EHEC virulence.

\section{ACKNOWLEDGEMENTS}

This work was supported by grants of the Deutsche Forschungsgemeinschaft ( $\mathrm{Ka} 717-2 / 2$, Graduiertenkolleg Infektiologie, Würzburg, Germany).

\section{REFERENCES}

Bauer, M. E. \& Welch, R. A. (1996). Characterization of an RTX toxin from enterohemorrhagic Eschericbia coli O157:H7. Infect Immun 64, 167-175.

Beaman, L. \& Beaman, B. L. (1984). The role of oxygen and its derivatives in microbial pathogenesis and host defense. Annu Rev Microbiol 38, 27-48.

Bortolussi, R., Vandenbroucke-Grauls, C. M. J. E., Van Asbeck, B. S. \& Verhoeff, J. (1987). Relationship of bacterial growth phase to killing of Listeria monocytogenes by oxidative agents generated by neutrophils and enzyme systems. Infect Immun 55, 3197-3203.

Brown, S. M., Howell, M. L., Vasil, M. L., Anderson, A. J. \& Hassett, D. J. (1995). Cloning and characterization of the kat $B$ gene of Pseudomonas aeruginosa encoding a hydrogen peroxide-inducible catalase: purification of $\mathrm{KatB}$, cellular localization, and demonstration that it is essential for optimal resistance to hydrogen peroxide. J Bacteriol 177, 6536-6544.

De Mendez, I., Young, K. R. J., Bignon, J. \& Lambre, C. R. (1991). Biochemical characteristics of alveolar macrophage-specific peroxidase activities in the rat. Arch Biochem Biophys 289, 319-323.

Dytoc, M., Soni, R., Cockerill, F., De Azavedo, J., Louie, M., Brunton, J. \& Sherman, P. (1993). Multiple determinants of verotoxin-producing Escherichia coli O157:H7 attachmenteffacement. Infect Immun 61, 3382-3391.

Farr, S. P. \& Kogoma, T. (1991). Oxidative stress responses in Escherichia coli and Salmonella typhimurium. Microbiol Rev 55, 561-585.

Forkl, H., Vandekerckhove, J., Drews, G. \& Tadros, M. H. (1993). Molecular cloning, sequence analysis and expression of the gene for catalase-peroxidase (CPEA) from the photosynthetic bacterium Rhodobacter capsulatus B10. Eur J Biocbem 214, 251-258.

Franzon, V. L., Arondel, J. \& Sansonetti, P. J. (1990). Contribution of superoxide dismutase and catalase activities to Shigella flexneri pathogenesis. Infect Immun 58, 529-535.

Fratamico, P. M., Bhaduri, S. \& Buchanan, R. L. (1993). Studies on Eschericbia coli serotype $0157: \mathrm{H} 7$ strains containing a $60-\mathrm{MDa}$ plasmid and on 60-MDa plasmid-cured derivatives. J Med Microbiol 39, 371-381.

Goebel, W., Leimeister Wachter, M., Kuhn, M., Domann, E., Chakraborty, T., Kohler, S., Bubert, A., Wuenscher, M. \& Sokolovic, Z. (1993). Listeria monocytogenes-a model system for studying the pathomechanisms of an intracellular microorganism. Zentralbl Bakteriol 278, 334-347. 
Griffin, P. M. (1995). Escherichia coli $\mathrm{O} 157: \mathrm{H} 7$ and other enterohemorrhagic Eschericbia coli. In Infections of the Gastrointestinal Tract, pp. 739-761. Edited by M. J. Blaser, P. D. Smith, J. D. Ravdin, H. B. Greenberg \& R. L. Guerrant. New York: Raven Press.

Griffin, P. M. \& Tauxe, R. V. (1991). The epidemiology of infections caused by Escherichia coli O157:H7, other enterohemorrhagic $E$. coli, and the associated hemolytic uremic syndrome. Epidemiol Rev 13, 60-98.

Hales, B. A., Hart, C. A., Batt, R. M. \& Saunders, J. R. (1992). The large plasmids found in enterohemorrhagic and enteropathogenic Eschericbia coli constitute a related series of transfer-defective Inc FIIA replicons. Plasmid 28, 183-193.

Hanahan, D. (1983). Studies on transformation of Eschericbia coli with plasmids. $J$ Mol Biol 166, 557-580.

von Heijne, G. (1986). A new method for predicting signal sequence cleavage sites. Nucleic Acids Res 14, 4683-4690.

Heimberger, A. \& Eisenstark, A. (1988). Compartmentalization of catalases in Escherichia coli. Biochem Biophys Res Commun 154, 392-397.

Heym, B., Zhang, Y., Poulet, S., Young, D. \& Cole, S. T. (1993). Characterization of the kat $G$ gene encoding a catalase-peroxidase required for the isoniazid susceptibility of Mycobacterium tuberculosis. J Bacteriol 175, 4255-4259.

Jacobs, C., Dubus, A., Monnaie, D., Normark, S. \& Frere, J. M. (1992). Mutation of serine residue 318 in the class $C$ beta-lactamase of Enterobacter cloacae 908R. FEMS Microbiol Lett 71, 95-100.

Kagaya, K., Miyakawa, Y., Watanabe, K. \& Fukazawa, Y. (1992). Antigenic role of stress-induced catalase of Salmonella typhimurium in cell-mediated immunity. Infect Immun 60, 1820-1825.

Karch, H., Heesemann, J., Laufs, R., O'Brien, A. D., Tacket, C. 0. \& Levine, M. M. (1987). A plasmid of enterohemorrhagic Eschericbia coli $\mathrm{O} 157: \mathrm{H} 7$ is required for expression of a new fimbrial antigen and for adhesion to epithelial cells. Infect Immun 55, 455-461.

Klotz, M. G. \& Hutcheson, S. W. (1992). Multiple periplasmic catalases in phytopathogenic strains of Pseudomonas syringae. Appl Environ Microbiol 58, 2468-2473.

Laemmli, U. K. (1970). Cleavage of structural proteins during the assembly of the head of bacteriophage T4. Nature 227, 680-685.

Loewen, P. C., Triggs, B. L., George, C. S. \& Hrabarchuk, B. E. (1985a). Genetic mapping of kat $G$, a locus that affects synthesis of the bifunctional catalase-peroxidase hydroperoxidase I in Escherichia coli. J Bacteriol 162, 661-667.

Loewen, P. C., Switala, J. \& Triggs Raine, B. L. (1985b). Catalases HPI and HPII in Escherichia coli are induced independently. Arcb Biochem Biophys 243, 144-149.

Loewen, P. C. \& Stauffer, G. V. (1990). Nucleotide sequence of kat $G$ of Salmonella typbimurium LT2 and characterization of its product, hydroperoxidase I. Mol Gen Genet 224, 147-151.

Loprasert, S., Negoro, S. \& Okada, H. (1989). Cloning, nucleotide sequence, and expression in Escherichia coli of the Bacillus stearotbermophilus peroxidase gene (per A). J Bacteriol 171, 4871-4875.

Louie, M., De Azavedo, J. C., Handelsman, M. Y., Clark, C. G., Ally, B., Dytoc, M., Sherman, P. \& Brunton, J. (1993). Expression and characterization of the eae $A$ gene product of Escherichia coli serotype O157: H7. Infect Immun 61, 4085-4092.

Markwell, M. A., Haas, S. M., Bieber, L. L. \& Tolbert, N. E. (1978). A modification of the Lowry procedure to simplify protein determination in membrane and lipoprotein samples. Anal Biochem 87, 206-210.

Morris, S. L., Nair, J. \& Rouse, D. A. (1992). The catalase-peroxidase of Mycobacterium intracellulare: nucleotide sequence analysis and expression in Escherichia coli. J Gen Microbiol 138, 2363-2370.

Myers, E. R., Dallmier, A. W. \& Martin, S. E. (1993). Sodium chloride, potassium chloride, and virulence in Listeria monocytogenes. Appl Environ Microbiol 59, 2082-2086.

O'Brien, A. \& Holmes, R. K. (1987). Shiga and Shiga-like toxins. Microbiol Rev 51, 206-220.

O'Brien, A. O., Lively, T. A., Chen, M. E., Rothman, S. W. \& Formal, S. B. (1983). Escherichia coli $\mathrm{O} 157: \mathrm{H} 7$ strains associated with haemorrhagic colitis in the United States produce a Shigella dysenteriae 1 (SHIGA) -like cytotoxin. Lancet i, 702.

O'Brien, A. D., Tesh, V. L., Donohue Rolfe, A., Jackson, M. P., Olsnes, S., Sandvig, K., Lindberg, A. A. \& Keusch, G. T. (1992). Shiga toxin: biochemistry, genetics, mode of action, and role in pathogenesis. Curr Top Microbiol Immunol 180, 65-94.

von Ossowski, I., Mulvey, M. R., Leco, P. A., Borys, A. \& Loewen, P. C. (1991). Nucleotide sequence of Eschericbia coli katE, which encodes catalase HPII. J Bacteriol 173, 514-520.

Pridmore, R. D. (1987). New and versatile cloning vectors with a kanamycin-resistance marker. Gene 56, 309-312.

Rosenberg, M. \& Court, D. (1979). Regulatory sequences involved in the promotion and termination of RNA transcription. Annu Rev Genet 13, 319-353.

Salmond, G. P. \& Reeves, P. J. (1993). Membrane traffic wardens and protein secretion in gram-negative bacteria. Trends Biocbem Sci 18, 7-12.

Sambrook J., Fritsch E. F. \& Maniatis T. (1989). Molecular Cloning: a Laboratory Manual. Cold Spring Harbor, NY: Cold Spring Harbor Laboratory.

Schmidt, H., Karch, H. \& Beutin, L. (1994a). The large-sized plasmids of enterohemorrhagic Eschericbia coli $\mathrm{O} 157$ strains encode hemolysins which are presumably members of the $E$. coli $\alpha$ hemolysin family. FEMS Microbiol Lett 117, 189-196.

Schmidt, H., Rüssmann, H., Schwarzkopf, A., Aleksic, S., Heesemann, J. \& Karch, H. (1994b). Prevalence of attaching and effacing Escherichia coli in stool samples from patients and controls. Int J Med Microbiol Virol Parasitol Infect Dis 281, 201-213.

Schmidt, H., Beutin, L. \& Karch, H. (1995). Molecular analysis of the plasmid-encoded hemolysin of Escherichia coli O157:H7 strain EDI 933. Infect Immun 63, 1055-1061.

Schmidt, H., Kernbach, C. \& Karch, H. (1996). Analysis of the EHEC bly operon and its location in the physical map of enterohaemorrhagic Eschericbia coli O157:H7. Microbiology 141, 907-914

Storz, G. \& Toledano, M. B. (1994). Regulation of bacterial gene expression in response to oxidative stress. Methods Enzymol 236, 196-207.

Tarr, P. I. (1995). Escherichia coli O157: H7: clinical, diagnostic, and epidemiological aspects of human infection. Clin Infect Dis 20,1-10.

Tesh, V. L. \& O'Brien, A. D. (1991). The pathogenic mechanisms of Shiga toxin and the Shiga-like toxins. Mol Microbiol 5, 1817-1822.

Toth, I., Cohen, M. L., Rumschlag, H. S., Riley, L. W., White, E. H., Carr, J. H., Bond, W. W. \& Wachsmuth, I. K. (1990). Influence of the 60-megadalton plasmid on adherence of Escherichia coli O157: H7 and genetic derivatives. Infect Immun 58, 1223-1231.

Triggs-Raine, B. L. \& Loewen, P. C. (1987). Physical characterization of katG, encoding catalase HPI of Escherichia coli. Gene 52, 121-128.

Triggs-Raine, B. L., Doble, B. W., Mulvey, M. R., Sorby, P. A. \& 
Loewen, P. C. (1988). Nucleotide sequence of kat $G$, encoding catalase HPI of Escberichia coli. J Bacteriol 170, 4415-4419.

Tzipori, S., Karch, H., Wachsmuth, K. I., Robins Browne, R. M., O'Brien, A. D., Lior, H., Cohen, M. L., Smithers, J. \& Levine, M. M. (1987). Role of a 60-megadalton plasmid and Shiga-like toxins in the pathogenesis of infection caused by enterohemorrhagic Escherichia coli $\mathrm{O} 157: \mathrm{H} 7$ in gnotobiotic piglets. Infect Immun 55, 3117-3125.

Tzipori, S., Wachsmuth, K. l., Smithers, J. \& Jackson, C. (1988). Studies in gnotobiotic piglets on non-O157:H7 Eschericbia coli serotypes isolated from patients with hemorrhagic colitis. Gastroenterology 94, 590-597.

Wadolkowski, E. A., Burris, J. A. \& O'Brien, A. D. (1990). Mouse model for colonization and disease caused by enterohemorrhagic Escherichia coli O157: H7. Infect Immun 58, 2438-2445.

Wayne, L. G. \& Diaz, G. A. (1986). A double staining method for differentiating between two classes of mycobacterial catalase in polyacrylamide electrophoresis gels. Anal Biochem 157, 89-92.
Welch, D. F. (1987). Role of catalase and superoxide dismutase in the virulence of Listeria monocytogenes. Ann Inst Pasteur 138, 265-268.

Welinder, K. G. (1991). Bacterial catalase-peroxidases are gene duplicated members of the plant peroxidase superfamily. Biochim Biophys Acta 1080, 215-220.

Wells, J. G., Davis, B. R., Wachsmuth, I. K., Riley, L. W., Remis, R. S., Sokolow, R. \& Morris, G. K. (1983). Laboratory investigation of hemorrhagic colitis outbreaks associated with a rare Escherichia coli serotype. J Clin Microbiol 18, 512-520.

Woodbury, W., Spencer, A. K. \& Stahman, M. A. (1971). An improved procedure using ferricyanide for detecting catalase isozymes. Anal Biochem 44, 301-305.

Yu, J. \& Kaper, J. B. (1992). Cloning and characterization of the eae gene of enterohaemorrhagic O157:H7. Mol Microbiol 6, 411-417.

Received 2 April 1996; revised 28 June 1996; accepted 3 July 1996. 